\title{
Evaluating the social determinants of teenage pregnancy: a temporal analysis using a UK obstetric database from 1950 to 2010
}

\author{
Stephen J McCall, ${ }^{1}$ Sohinee Bhattacharya, ${ }^{1}$ Emmanuel Okpo, ${ }^{2}$ Gary J Macfarlane ${ }^{1}$
}

${ }^{1}$ Epidemiology Group, School of Medicine and Dentistry, University of Aberdeen, Aberdeen, UK

${ }^{2}$ Department of Public Health, National Health Service (NHS) Grampian, Aberdeen, UK

\section{Correspondence to} Stephen J McCall, Department of Obstetrics and Gynaecology, Dugald Baird Centre, Aberdeen Maternity Hospital, University of Aberdeen, Cornhill Road, Aberdeen AB25 2ZL, UK; s.mccall.09@aberdeen.ac.uk

Received 28 March 2014 Revised 21 July 2014 Accepted 29 August 2014 Published Online First 16 September 2014

\section{ABSTRACT \\ Background Teenage pregnancy is a known social} problem which has been previously described using a number of deprivation measures. This study aimed to explore the temporal patterns of teenage pregnancy in Aberdeen, Scotland and to assess the discriminating ability of three measures of socioeconomic status. Methods This was a population-based study from 1950 to 2010, using data from the Aberdeen Maternity Neonatal Databank (AMND). The main outcome variable was conceptions occurring in women aged less than 20 years. This study used two area-based measures, the Scottish Index of Multiple Deprivation (SIMD) and the Carstairs index, and one individual-based measure the Social Class based on Occupation (SCO). These measures were compared for their association with teenage conceptions using logistic regression models. The models were used to determine receiver operating characteristic (ROC) curves showing the discriminating ability of the measures.

Results There was an overall decline in teenage conceptions over the 60-year period, but an increase in the rate ratio for deprived areas. All the measures of socioeconomic status were highly associated with teenage pregnancy. The adjusted OR of SIMD and teenage conception was 5.72 (95\% Cl 4.62 to 7.09), which compared the most deprived decile with the least deprived decile. The use of ROC curves showed that socioeconomic measures performed better than chance at determining teenage conceptions $\left(\chi^{2}=21.67\right.$, $p \leq 0.0001)$. They further showed that the SIMD had the largest area under the curve (AUC) with a value of 0.81 (95\% Cl 0.80 to 0.82 ), followed by the Carstairs index with an AUC of $0.80(95 \% \mathrm{Cl} 0.78$ to 0.80$)$, then by SCO with an AUC of $0.79(95 \% \mathrm{Cl} 0.78$ to 0.80$)$. Conclusions Despite a slight decline in teenage pregnancies over the past decades, there is still an evident association between deprivation and teenage pregnancy. This study shows that all the measures of socioeconomic status were highly associated with teenage pregnancy, with the SIMD having the greatest discriminatory effect.

\section{INTRODUCTION}

CrossMark

To cite: McCall $S J$, Bhattacharya S, Okpo E, et al. J Epidemiol Community Health 2015;69:49-54.
Despite a decline in recent decades, the UK has the highest teenage pregnancy rate in Western Europe, a rate that is double that of Germany and six times higher than that of the Netherlands. ${ }^{1}$ Around 90\% of pregnancies in 15-19-year-olds are unwanted. ${ }^{2}$ This is confirmed by the disproportionately high number of terminations occurring in this age group. ${ }^{2}$ These unintended pregnancies cost the
National Health Service (NHS) approximately $£ 63$ million every year. ${ }^{4}$ As a result, adolescent pregnancies have remained at the forefront of national policy. The Scottish government in particular aimed to reduce pregnancies in 13-15-year-olds by $20 \%$ by $2010 .^{2}{ }^{5-7}$

Unlike many other clinical and public health problems, teenage pregnancy has an aetiology that is mainly derived from social factors. It is very apparent that there are clear spatial variations in teenage pregnancy, as it is well established that teenage pregnancies are associated with deprivation. ${ }^{8} 9$ However, deprivation socioeconomic status is a multifactorial and subjective term. This makes it very difficult to measure which is reflected in the variety of measures used in research and policy. ${ }^{10}$ Many studies have used aggregated area-based measures to assess an association; but these measures are susceptible to the ecological fallacy. Therefore, the individual level socioeconomic measures may consequently interact differently with teenage conceptions. With a number of deprivation measures available to quantify deprivation, this study seeks to examine the relationship between these measures and teenage conception using a temporal approach. There is little current evidence examining the temporal relationship of teenage pregnancy with deprivation measures, and no paper has established which deprivation measure best describes an association with teenage pregnancy. This study had two main aims; the first assessed the temporal variations of teenage conceptions in Aberdeen City. The second aim assessed the discriminating ability of each socioeconomic measure in relation to teenage conception.

\section{METHODS}

Ethics

Permission for the use of the data was approved by the steering committee of the Aberdeen Maternity Neonatal Databank (AMND). Formal ethical approval was not necessary as only anonymised data were used. The study followed the Information Services Division's (ISD) statistical disclosure control procedure.

\section{Data source and study design}

This was a registry-based study, using individual level data provided by the AMND between 1950 and 2010. The AMND is a routinely collected obstetric database in Aberdeen city; all the variables were collected at the individual level using the obstetric records of the mother. The AMND automatically uses the mother's postcode to provide 
each birth with a deprivation category. The variables obtained included: age of mother at delivery, mother's age at conception, marital status, smoking status, gestational age at the end of pregnancy (weeks), Carstairs index, Scottish Index of Multiple Deprivation (SIMD), outcome of pregnancy (miscarriage, live birth, neonatal death or stillbirth), history of an induced abortion, postcode sector, mother's race and the Social Class based on Occupation (SCO) of the mother and father. The outcome variable was teenage conception; this study defined teenage conception as a spontaneous abortion, missed abortion, stillbirth, neonatal death or delivery in women aged 11-19 years. This was calculated by subtracting the gestation age from the maternal age at delivery or pregnancy outcome. This study examined singleton teenage conceptions in first-time mothers. The breakdown of the measure is as follows: spontaneous abortion $(0.2 \%)$, missed abortion $(0.1 \%)$, stillbirth $(0.9 \%)$, neonatal death $(0.9 \%)$ and live birth $(98.1 \%)$. The requested data contained information on births from 1 January 1950 to 31 December 2010, and over this period there were 21662 (19.4\%) teenage conceptions in Aberdeen city with a total of 111583 conceptions.

\section{Exposures}

The exposures of this study were the different measures of socioeconomic status, and both individual level measures and area-based measures were utilised. This study compared three measures of socioeconomic status, the SIMD, the Carstairs index and SCO.

The SIMD and the Carstairs index are considered to be areabased measures. These were assigned to each patient through their postcode (a postcode is assigned to each area in the UK by Royal Mail, allowing the delivery of mail). The Carstairs index is a relative measure of material deprivation that uses census data by taking into account four unweighted indicators (social class, overcrowding, car ownership and unemployment) giving a ranked score for each area in Scotland. The scores in Scotland were ranked from 1 to 8 , with 1 being the least deprived and 8 being the most deprived; however, no area in Aberdeen has a score below the six category. The Carstairs index was available from 1980 to 2010.

The second area-based measure was the SIMD; it is a relative measure that has 38 contributing factors with 7 weighted domains including employment (22\%), income (28\%), access to services (9\%), crime (5\%), health (14\%), housing (2\%) and education (14\%). A single deprivation score was created for each postcode which ranked the scores into deciles, with 1 being the least deprived area and 10 being the most deprived area. ${ }^{11}$ Analysis using the SIMD was restricted from 2000 to $2010 .{ }^{12}$

SCO was used as the main individual measure of socioeconomic status. This measure spans the whole timescale of the AMND from 1950 to 2010. The combined scores were used to create the Registrar General's Occupational Social Class, which has six groups: professional (I), managerial (II), skilled nonmanual (IIInm), skilled manual (IIIm), semiskilled (IV) and unskilled (V). This measure was derived by using either the partner's or father's occupation to give each birth a measure of social class. The mother's own occupation was used to calculate the social class where paternal social class was missing, for example, in single mothers. The paternal SCO was available in $78347(69.3 \%)$ of the patients, while the mother's occupation was only available in $39814(35.2 \%)$ of the patients; the combined measure provided 82922 patients with SCO data.

The three covariates included in the analysis were smoking (yes, no or previous smoker), ethnicity (Caucasian or other) and marital status (cohabiting, married or non-cohabiting). These were all categorical variables and each was assessed for an association with teenage pregnancy. We limited multivariate analysis to 1985 onwards due to the availability of the covariate variables.

\section{Missing data}

Only $1.3 \%$ of mother's age at conception was missing from the data set. As each socioeconomic measure was introduced at different time periods, this resulted in different sample sizes for each measure, and the sample size can be seen in table 2 . Complete case analysis was used in the analysis.

\section{Statistical analysis}

The data set was cleaned of impossible values and the data were then stratified and recoded. Temporal analysis was completed using bivariate Poisson regression models. A bivariate Poisson regression was used to estimate the rate ratio of teenage pregnancy by a 5 -year period when comparing the unskilled SCO with the professional SCO, and when comparing the most deprived Carstairs category with the least deprived Carstairs category. The SIMD was only available from 2000, and thus was excluded from the temporal analysis. Absolute risk for teenage conception was calculated using the total number of pregnancies in the cohort in each 5-year period; this was also calculated for professional and unskilled SCO occupations for each time period and presented as percentages. Annual percentage change in teenage conception was also calculated for each time period.

An unadjusted analysis was completed using Pearson $\chi^{2}$ tests between teenage pregnancy, the measures of socioeconomic status and the covariates. Analysis was limited from 1985 onwards due to the availability of covariate variables. Logistic regression analysis was completed using a binary outcome (Teenage pregnancy Yes $=1, \mathrm{No}_{1}=0$ ) against predictor variables. Thereafter, three separate models for teenage pregnancies were constructed for the three different measures of social deprivation, adjusting for the same covariates of ethnicity, smoking and marital status in the model. The results from each model are presented as an OR with a 95\% CI. ${ }^{13}$ This analysis was carried out using SPSS V.20 (Chicago, Illinois, USA).

A receiver operating characteristic (ROC) curve was used to compare the discriminating ability of the previous logistic regression models. A combination command allowed the comparison of ROC curves for each model; this test shows whether the areas under the curve (AUC) for the models are equal. A gold standard ROC curve compared the SIMD model with other models to test for statistical significance. This analysis was carried out using Stata V.12 (STATA Corp, Texas, USA). The sensitivity, specificity and positive predictive value are also presented for the predicted outcomes from each individual logistic model.

\section{RESULTS \\ Temporal trends}

Table 1 highlights that the absolute rate of teenage conception has been declining since 1965-1969. From the period 19651969 to $2005-2010$, there has been a decline of $22.4 \%$. Table 1 illustrates that the declining trend has been mirrored in the unskilled and professional social classes. Figure 1 shows the rate ratio of teenage pregnancy by a 5 -year period in the unskilled social class and in the most deprived Carstairs category. In contrast to the absolute rates, the rate ratio among women in the most deprived categories has been increasing, apart from the most recent 5-year period, when compared with the least 
Table 1 Absolute rate of teenage conception across time

\begin{tabular}{|c|c|c|c|c|c|c|c|}
\hline Year & $\begin{array}{l}\text { Absolute rate } \\
\text { of teenage } \\
\text { conception, } n \\
(\%)\end{array}$ & $\begin{array}{l}\text { Total number } \\
\text { of conceptions } \\
\text { in the sample }\end{array}$ & $\begin{array}{l}\text { Annual } \\
\text { percentage } \\
\text { change in } \\
\text { teenage } \\
\text { conception } \\
\text { (year 1; \%) }\end{array}$ & $\begin{array}{l}\text { Absolute rate of } \\
\text { teenage } \\
\text { conception in the } \\
\text { unskilled } \\
\text { occupational social } \\
\text { class, } n(\%)\end{array}$ & $\begin{array}{l}\text { Absolute rate of } \\
\text { teenage } \\
\text { conception in the } \\
\text { professional } \\
\text { occupational social } \\
\text { class, } \mathrm{n}(\%)\end{array}$ & $\begin{array}{l}\text { Absolute } \\
\text { difference } \\
\text { between the } \\
\text { unskilled and } \\
\text { professional } \\
\text { social class (\%) }\end{array}$ & $\begin{array}{l}\text { Denominator for } \\
\text { Social Class } \\
\text { based on } \\
\text { Occupation* }\end{array}$ \\
\hline 1950-1954 & $1027(18.3)$ & 5597 & 6.06 & $145(3.5)$ & $6(0.1)$ & 3.4 & 4116 \\
\hline 1955-1959 & 1276 (19.7) & 6468 & 4.76 & $204(3.4)$ & $12(0.2)$ & 3.5 & 5923 \\
\hline 1960-1964 & $1519(24.8)$ & 6124 & 10.37 & $206(3.7)$ & $26(0.5)$ & 3.2 & 5502 \\
\hline 1965-1969 & 2149 (34.4) & 6242 & -1.20 & $290(5.4)$ & $36(0.7)$ & 4.7 & 5393 \\
\hline 1970-1974 & 2046 (33.6) & 6091 & 2.94 & $309(5.7)$ & $23(0.4)$ & 5.3 & 5376 \\
\hline 1975-1979 & $2287(25.0)$ & 9141 & 0.82 & 131 (3.9) & $10(0.3)$ & 3.6 & 3395 \\
\hline 1980-1984 & $2362(20.5)$ & 11507 & -1.34 & $187(2.4)$ & $16(0.2)$ & 2.2 & 7633 \\
\hline 1985-1989 & 2235 (17.8) & 12556 & -1.24 & $230(2.3)$ & $13(0.1)$ & 2.2 & 10184 \\
\hline 1990-1994 & $2124(15.8)$ & 13483 & -6.06 & $179(1.8)$ & $12(0.1)$ & 1.7 & 9846 \\
\hline 1995-1999 & 1609 (14.6) & 11002 & -3.17 & $137(1.6)$ & $10(0.1)$ & 1.5 & 8358 \\
\hline 2000-2004 & $1405(14.3)$ & 9828 & 3.10 & $121(1.8)$ & $9(0.1)$ & 1.7 & 6568 \\
\hline $2005-2010$ & $1623(12.0)$ & 13499 & - & $110(1.0)$ & $14(0.1)$ & 0.9 & 10628 \\
\hline
\end{tabular}

*The denominator differed from the total number of conceptions due to missing values in the Social Class based on Occupation.

deprived group. The rate ratio of teenage pregnancy in the unskilled SCO compared with the professional SCO has increased from a rate ratio of 7.33 (95\% CI 3.24 to 16.59$)$ in $1950-1955$ to a rate ratio of 25.72 (95\% CI 14.75 to 44.85 ) in 2005-2010. The rate ratio of teenage pregnancy in the most deprived Carstairs category compared to the least deprived category has increased from a rate ratio of 6.74 (95\% CI 4.97 to 9.14 ) in 1980-1984 to a rate ratio of 8.14 (95\% CI 6.5 to 10.18 ) in 2005-2010.

\section{Bivariate comparison}

Teenage conception accounted for 19.2\% $(n=21662)$ of the conceptions in this cohort. The sample size of teenage conception within each measure of socioeconomic status is found in table 2. When examining the SIMD, it shows that the proportion of teenage conceptions was largest in the most deprived decile in comparison with the least deprived decile $(17.6 \%$ vs $5.6 \%)$, $\mathrm{p} \leq 0.0001$. Similarly, when examining the Carstairs index, the largest proportion of teenage pregnancies occurred in the most deprived category in comparison with the least deprived category (15.9\% vs $4 \%), p \leq 0.0001$. The majority of teenage maternities occurred in the lower social classes (IIIm, IV and V).

\section{Logistic regression}

Table 3 shows the association between socioeconomic measures and teenage pregnancy, while adjusting for smoking, marital status and ethnicity. All measures showed a significant association with teenage pregnancy. In fact, each measure showed a gradual increase in the strength of the association, with increasing deprivation category, decile or occupational class. In the Carstairs index, when comparing the most deprived category with the least deprived category, the OR was 4.69 (95\% CI 4.08 to 5.40$), \mathrm{p} \leq 0.0001$. When comparing the most deprived decile with the least deprived decile using the SIMD, the OR was higher at $5.72(4.62$ to 7.09$), \mathrm{p} \leq 0.0001$. The OR increased even more when using the SCO; by comparing the unskilled occupation (V) with the professional occupation, the OR was 14.77 (95\% CI 11.13 to 19.59 ), $\mathrm{p} \leq 0.0001$. Therefore, all the measures show that socioeconomic status is associated with an increased likelihood of teenage pregnancy.

\section{Receiver operating characteristic curves}

Table 4 shows that the SCO had a larger overall correct classification estimate than the SIMD with $89.77 \%$ vs $86.68 \%$, when the models were tested independently, although this test was unable to identify whether the models were statistically different. However, when the outputs of these models were combined in the analysis, the SIMD had a slightly larger AUC than the other measures with an AUC of 0.81 (95\% CI 0.80 to 0.82). The Carstairs index had an AUC of 0.80 (95\% CI 0.78 to $0.80)$, and the SCO had an AUC of 0.79 (95\% CI 0.78 to 0.80). As the CIs overlap slightly, the gold standard ROC curve was calculated to establish if there was a statistical difference between the SIMD and other measures, and the results are as seen in table 4. This analysis compared the SIMD with the other measures, and the analysis showed that the SIMD is significantly different from each measure (SIMD vs Carstairs $\chi^{2}=18.1, p \leq 0.0001$, SIMD vs SCO $\left.\chi^{2}=11.39, p<0.001\right)$. The size and direction of this relationship is shown by the AUC, and this value shows that the SIMD is the better discriminating measure with an AUC of 0.81 (95\% CI 0.80 to 0.82).

\section{DISCUSSION \\ Main findings}

There has been a temporal change in teenage conception, with an overall decline in the number of teenage conceptions since 1950 in Aberdeen city. This is the first paper to examine the relationship of teenage pregnancy with deprivation over a 60 -year time period. The decline in the proportion of teenage pregnancies, however, masks a large increase in the rate ratio of teenage pregnancy in the unskilled SCO and in the most deprived Carstairs category over time, indicating an increase in social disparity in the area. Multivariate analysis highlighted a strong association between each socioeconomic measure and teenage pregnancy; all the measures appear to be able to classify teenage pregnancy, but the SIMD has the largest discriminatory effect.

\section{Strengths and limitations}

The provision of individual level social and clinical data from 1950 to 2010 was provided by the AMND, which is one of the longest running continuous obstetric databases in Europe. The 
Table 2 Comparing the demographic characteristics of teenage and non-teenage conceptions by each socioeconomic measure and covariates

\begin{tabular}{|c|c|c|c|}
\hline \multicolumn{4}{|l|}{ Descriptive table } \\
\hline & Teenage pregnancy, n (\%) & $\begin{array}{l}\geq 20 \text {-Year-old } \\
\text { conceptions, } \mathrm{n}(\%)\end{array}$ & p Value \\
\hline \multicolumn{4}{|c|}{ Scottish Index of Multiple Deprivation* $(n=21821$ ) } \\
\hline Least deprived & $160(5.6)$ & $3587(18.9)$ & $<0.001$ \\
\hline 2 & $206(7.2)$ & $3500(18.5)$ & \\
\hline 3 & $275(9.6)$ & $3199(16.9)$ & \\
\hline 4 & $163(5.7)$ & $1493(7.9)$ & \\
\hline 5 & $258(9)$ & $1577(8.3)$ & \\
\hline 6 & $344(12.0)$ & $1705(9)$ & \\
\hline 7 & $234(8.2)$ & $902(4.8)$ & \\
\hline 8 & $408(14.3)$ & $1407(7.4)$ & \\
\hline 9 & $302(10.6)$ & $845(4.5)$ & \\
\hline Most deprived & $506(17.7)$ & $750(4.0)$ & \\
\hline \multicolumn{4}{|c|}{ Carstairs indext $(n=62331)$} \\
\hline 1 & $400(4)$ & $7791(14.9)$ & $<0.001$ \\
\hline 2 & $1878(18.9)$ & $17782(34)$ & \\
\hline 3 & $1751(17.6)$ & $10226(19.5)$ & \\
\hline 4 & $3241(32.5)$ & $10944(20.9)$ & \\
\hline 5 & $1102(11.1)$ & $3320(6.3)$ & \\
\hline 6 & $1588(15.9)$ & $2308(4.4)$ & \\
\hline \multicolumn{4}{|c|}{ Social Class based on Occupation ( $\mathrm{n}=82$ 922) } \\
\hline I & $187(1.4)$ & $8449(12.1)$ & $<0.001$ \\
\hline ॥ & $870(6.6)$ & $13573(19.5)$ & \\
\hline IIInm & $1327(10.1)$ & $8958(12.8)$ & \\
\hline IIIm & 5195 (39.5) & $20967(30.1)$ & \\
\hline IV & $3337(25.3)$ & $13482(19.2)$ & \\
\hline $\mathrm{V}$ & $2249(17.1)$ & $4328(6.2)$ & \\
\hline \multicolumn{4}{|c|}{ Marital status ( $n=111338)$} \\
\hline Non-cohabiting & $2359(10.9)$ & $8206(9.1)$ & $<0.001$ \\
\hline Cohabiting & $8451(39.1)$ & $9005(10.0)$ & \\
\hline Married & $10792(50.0)$ & $72525(80.8)$ & \\
\hline \multicolumn{4}{|l|}{ Ethnicity (n=64 246) } \\
\hline Caucasian & $10816(99.3)$ & $51622(96.8)$ & $<0.001$ \\
\hline Other & $81(0.7)$ & $1727(3.2)$ & \\
\hline \multicolumn{4}{|c|}{ Smoking status $(n=76690)$} \\
\hline Former smoker & $971(6.6)$ & $4091(6.6)$ & $<0.001$ \\
\hline Non-smoker & $5311(36.1)$ & $40296(65)$ & \\
\hline Smoker & 8410 (57.2) & $17611(28.4)$ & \\
\hline
\end{tabular}

AMND has rigorous protocols in place to ensure the validity and reliability of the data. The use of consistent measurement criteria in the collection of the data has reduced information bias within the study.

A potential weakness of this study is that it may be at risk of residual confounding as there are variables that the database did not have access to such as contraceptive usage, educational level and housing type, which may be associated with teenage pregnancy. ${ }^{14}$ However, the use of deprivation measures attempts to accommodate for this, as these measures are based on a number of social factors that may be associated with teenage pregnancy. ${ }^{6}$ Yet these measure themselves are only a proxy of deprivation and have limitations. ${ }^{15}$ Area-based measures use postcodes; these are not designed for the classification of populations by deprivation category; therefore, by default, these measures may be at risk of misclassifying. Similarly, the use of paternal social class may misclassify the households' social class; this may be more apparent in recent decades where there has been a change of gender roles within households in the UK.

\section{Findings and context}

The temporal changes

This is the first study to examine the temporal relationship of teenage conceptions with a deprivation measure over a 60 -year period, and it highlights large temporal variation in teenage conceptions across this period. The temporal change of teenage conceptions exhibited in Aberdeen follows a similar trend to the English and Welsh maternities, as there is a peak in maternities during the late 1960 s, followed by a decline in teenage maternities since the mid-1970s. This observed decline in the rate of conceptions in the unskilled and professional SCO follows a similar decline seen in the overall numbers of teenage conceptions. ${ }^{16}$ The decline in teenage pregnancy rates followed the decline in fertility in the general population, and this study 
Table 3 Multivariate analysis for each socioeconomic measure using data from the Aberdeen Maternity Neonatal Databank

\begin{tabular}{|c|c|c|c|c|c|c|c|c|}
\hline \multicolumn{9}{|c|}{ Adjusted models* } \\
\hline \multicolumn{3}{|c|}{ Scottish Index of Multiple Deprivation model } & \multicolumn{3}{|c|}{ Carstairs index model } & \multicolumn{3}{|c|}{ Social Class based on Occupation model } \\
\hline & OR & $95 \% \mathrm{Cl}$ & & OR & $95 \% \mathrm{Cl}$ & & OR & $95 \% \mathrm{Cl}$ \\
\hline \multicolumn{9}{|c|}{ Measure category } \\
\hline Least deprived & 1 & & Least deprived & 1 & & I & 1 & \\
\hline 2 & 1.23 & (0.97 to 1.54$)$ & 2 & 1.55 & (1.35 to 1.76$)$ & ॥ & 2.44 & (1.83 to 3.25 ) \\
\hline 3 & 1.54 & (1.24 to 1.92$)$ & 3 & 2.40 & (2.10 to 2.74 ) & IIInm & 4.93 & (3.71 to 6.55 ) \\
\hline 4 & 1.68 & (1.31 to 2.16$)$ & 4 & 2.98 & (2.62 to 3.40$)$ & IIIm & 7.01 & (5.34 to 9.20$)$ \\
\hline 5 & 2.38 & (1.90 to 2.98 ) & 5 & 3.54 & (3.07 to 4.07 ) & IV & 7.03 & (5.35 to 9.23 ) \\
\hline 6 & 2.63 & (2.12 to 3.27$)$ & Most deprived & 4.69 & $(4.08$ to 5.40$)$ & V & 14.77 & (11.13 to 19.59$)$ \\
\hline 7 & 2.96 & (2.34 to 3.75$)$ & & & & & & \\
\hline 8 & 3.13 & (2.53 to 3.86$)$ & & & & & & \\
\hline 9 & 3.47 & (2.77 to 4.36 ) & & & & & & \\
\hline Most deprived & 5.72 & (4.62 to 7.09 ) & & & & & & \\
\hline
\end{tabular}

shows that teenage conceptions follow this described trend. ${ }^{16}$ Despite an overall decline in the rate of teenage conception for the unskilled SCO, the rate ratio in this group has increased since 1950-1954. A possible explanation for this is the transition of middle-class women pursuing a career and delaying childbearing, while women in deprived areas have little motivation to delay childbearing.

\section{Teenage pregnancies and socioeconomic measures}

The association between teenage pregnancy and area-based deprivation indices observed in this study is consistent with the findings of other studies, with teenage maternities more likely to occur in the most deprived areas in comparison to most affluent areas. $^{1} 2891718$ Teenage pregnancy is a common outcome with a high prevalence in this population; this paper has presented ORs, which should be interpreted as such.

There are a number of reasons for the strong association between teenage pregnancy and deprivation, reported in the literature. Girls from lower socioeconomic areas may perceive their environment more negatively. Therefore, they are more likely to engage in risky sexual behaviour at a younger age. Consequently, these girls are less likely to use contraception due to behavioural problems or lack of education or aspira-

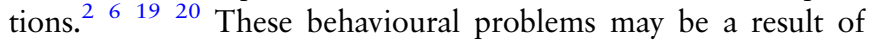
the individual, societal, familial and environmental factors of living in a deprived area. These risk factors have been further developed into the problem-behaviour theory, which states that living in an environment that is characterised by a lack of social cohesion, poor academic performance and a high level of poverty can increase and encourage antisocial behaviours among teenagers. ${ }^{6}$

This study is the first to compare the discriminating abilities of socioeconomic measures related to teenage pregnancy. Measures which are made up of more social indicators and social behaviours are argued to be better at explaining area effects. ${ }^{1}$ The results from this study support this proposition, as the best discriminating measure for teenage pregnancy was the SIMD. The SIMD measure is the most elaborate deprivation measure available in Scotland, which aims to reflect the multifaceted characteristics of deprived areas. ${ }^{12} 15$

Implications for public health practice and policy: the results from this study highlight the importance of social disparity and small area effects on teenage conceptions in a relatively affluent region in the North East of Scotland that has undergone huge
Figure 1 Trend of teenage conceptions and the rate ratio of teenage pregnancy in women who are either in the most deprived Carstairs category or the unskilled occupational social class category (SCO, Social Class based on Occupation).

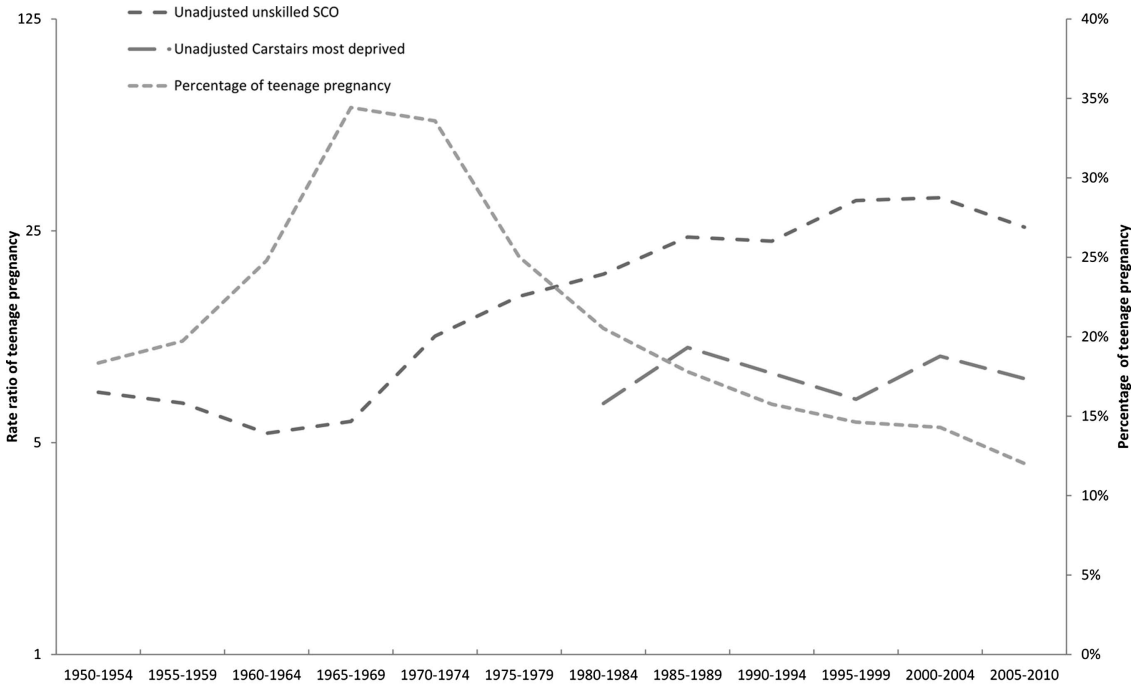


Table 4 Receiver operating characteristic curve and diagnostic test values for the logistic regression models

\begin{tabular}{|c|c|c|c|c|c|c|c|c|c|c|}
\hline \multirow[b]{2}{*}{ Carstairs index } & \multirow{2}{*}{$\begin{array}{l}\text { Area under the } \\
\text { receiver operating } \\
\text { characteristic curve }\end{array}$} & \multirow{2}{*}{$\begin{array}{l}95 \% \mathrm{Cl} \\
0.78 \text { to } 0.80\end{array}$} & \multirow{2}{*}{$\begin{array}{l}\text { Sensitivity } \\
(\%)\end{array}$} & \multirow{2}{*}{$\begin{array}{l}\text { Specificity } \\
(\%)\end{array}$} & \multirow{2}{*}{$\begin{array}{l}\begin{array}{l}\text { PPV } \\
(\%)\end{array} \\
37.76\end{array}$} & \multirow{2}{*}{$\begin{array}{l}\begin{array}{l}\text { NPV } \\
(\%)\end{array} \\
85.80\end{array}$} & \multirow{2}{*}{ 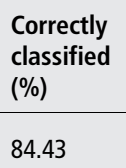 } & \multicolumn{3}{|c|}{$\begin{array}{l}\text { Gold standard receiver operating } \\
\text { characteristic curve }\end{array}$} \\
\hline & & & & & & & & & $\chi^{2}$ Value & $\mathrm{p}$ Value \\
\hline sco & 0.79 & 0.78 to 0.80 & 2.94 & 99.59 & 44.10 & 90.08 & 89.77 & $\begin{array}{l}\text { Scottish Index of } \\
\text { Multiple Deprivation } \\
\text { vs Carstairs }\end{array}$ & 18.1 & $\leq 0.001$ \\
\hline $\begin{array}{l}\text { Scottish Index of } \\
\text { Multiple } \\
\text { Deprivation }\end{array}$ & 0.81 & 0.80 to 0.82 & 6.00 & 98.88 & 44.72 & 87.43 & 86.68 & $\begin{array}{l}\text { Scottish Index of } \\
\text { Multiple Deprivation } \\
\text { vs SCO }\end{array}$ & 11.39 & $<0.001$ \\
\hline \multicolumn{3}{|c|}{$\chi^{2}=21.67(p \leq 0.001)$} & \multicolumn{8}{|c|}{ Tested independently for each model } \\
\hline
\end{tabular}

economic and social transition over time. The average rate of teenage pregnancy over time and large regional space hides the pockets of deprivation and disparity and associated increase in teenage pregnancies. This suggests that at least for this region, interventions to reduce teenage pregnancies should be targeted at specific localised deprived areas to maximise their effects. Importantly, the difference seen between the SIMD and other measures is unlikely to have a substantial clinical impact as all the measures are highly associated with teenage pregnancy.

\section{CONCLUSIONS}

This is the first study to examine the temporal relationship of teenage conceptions with a deprivation measure over such a long time period; it has found that there were significant variations in the rates of teenage conceptions over time in Aberdeen city. This study uniquely highlights the importance of examining teenage conceptions by time and space as both these dimensions highlight variations in teenage conceptions.

\section{What is already known on this subject}

Teenage pregnancy is known to have a strong association with deprivation. However, the temporal relationship with deprivation has yet to be fully explored and it is unclear which measure best describes an association with teenage pregnancy.

\section{What this study adds}

This study shows that the rate ratio of teenage pregnancy increased over time for women living in deprived areas or in the unskilled occupational social classes. All the measures of socioeconomic status were highly associated with teenage pregnancy, with the Scottish Index of Multiple Deprivation having the greatest discriminatory effect.

\footnotetext{
Acknowledgements The authors thank Dr Amalraj Raja who provided statistical advice and to the Data Management team, University of Aberdeen for data extraction. They also thank Helen King and Margery Heath for reviewing the manuscript.
}

Contributors SJM contributed to the study design, data analysis, interpretation and to the writing of the manuscript. SB contributed to the study conception, data acquisition and data interpretation, and also reviewed and revised the article. EO contributed to the study design and also read and contributed to the article. GJM contributed to the study conception, study design and data interpretation, and also reviewed and revised the article. All authors gave their approval for the manuscript to be published.

\section{Competing interests None.}

Provenance and peer review Not commissioned; externally peer reviewed.

Data sharing statement Data can be obtained from the AMND. Please see http://www.abdn.ac.uk/amnd for details.

\section{REFERENCES}

1 McCulloch A. Teenage childbearing in Great Britain and the spatial concentration of poverty households. J Epidemiol Community Health 2001;55:16-23.

2 Klein JD, Barratt MS, Blythe MJ, et al. Adolescent pregnancy: current trends and issues. Pediatrics 2005:116:281-6.

3 Information Service Division-Scotland. Teenage pregnancy. Edinburgh, Scotland: ISD, 2012. [eReport] http://www.isdscotland.org/Health-Topics/Sexual-Health/Publications/ 2013-06-25/2013-06-25-TeenPreg-Report.pdf?14291018248 (accessed on 15 Aug 2012).

4 Teenage Pregnancy Strategy Evaluation Team. Annual report synthesis 2002. London: Teenage Pregnancy Unit, 2003.

5 Aldridge $\mathrm{H}$, Parekh A, Maclnnes T, et al. Monitoring poverty and social exclusion 2011. Joseph Rowntree Foundation, 2011. http://www.jrf.org.uk/sites/files/jrf/ poverty-social-exclusion-assessment-full.pdf (accessed Sep 2014).

6 Coyne CA, D'Onofrio BM. Some (but not much) progress toward understanding teenage childbearing: a review of research from the past decade. Adv Child Dev Behav 2012;42:113-52.

7 Social Exclusion Unit. Teenage pregnancy: report by the Social Exclusion Unit. London: Stationery Office, 1999.

8 McLeod A. Changing patterns of teenage pregnancy: population based study of small areas. BMJ 2001;323:199-203.

9 Uren Z, Sheers D, Dattani N. Teenage conceptions by small area deprivation in England and Wales, 2001-2002. Health Stat Q 2007;33:34-9.

10 Galobardes B, Lynch J, Smith GD. Measuring socioeconomic position in health research. Br Med Bull 2007;81-82:21-37.

11 Information Service Division, Scotland. Deprivation. Scotland: ISD Archive, 2009

12 The Scottish Government. Scottish Index of Multiple Deprivation 2009-National Report. The Scottish Government, 2009. http://www.scotland.gov.uk/Resource/Doc/ 289599/0088642.pdf (accessed 5 Sep 2013).

13 Peacock JL, Kerry S. Presenting medical statistics from proposal to publication: a step-by-step guide. Oxford University Press, 2007.

14 Thadhani R, Tonelli M. Cohort studies: marching forward. Clin J Am Soc Nephrol 2006;1:1117-23.

15 Deas I, Robson B, Wong C, et al. Measuring neighbourhood deprivation: a critique of the Index of Multiple Deprivation. Environ Plann C 2003;21:883-904.

16 Macfarlane AJ, Mugford M. Birth counts: statistics of pregnancy and childbirth. 2nd edn. London: The Stationery Office, 2000.

17 Vikat A, Rimpela A, Kosunen E, et al. Sociodemographic differences in the occurrence of teenage pregnancies in Finland in 1987-1998: a follow up study. J Epidemiol Community Health 2002;56(9):659-68.

18 Garlick R, Ineichen B, Hudson F. The UPA score and teenage pregnancy. Public Health 1993;107:135-9.

19 Johns SE. Perceived environmental risk as a predictor of teenage motherhood in a British population. Health Place 2011;17:122-31.

20 Morrison DM, Shaklee H. Poor contraceptive use in the teenage years: situational and developmental interpretations. Adv Adolesc Mental Health 1990;4:51-69. 